\title{
ОЦЕНКА ПОТЕНЦИАЛА ИМПОРТОЗАМЕЩЕНИЯ ОТРАСЛЕЙ ОТЕЧЕСТВЕННОЙ ПРОМЫШЛЕННОСТИ И ПРИНЦИП ОТБОРА ПРОЕКТОВ ПО ИМПОРТОЗАМЕЩЕНИЮ "
}

\author{
(C) 2018 Исаева Елена Владимировна \\ начальник Центра управленческих компетенций \\ Омский государственный технический университет \\ 644050, Омск, Пр. Мира, д. 11 \\ E-mail:ev_isaeva@mail.ru
}

В статье рассмотрен подход к оценке потенциала отраслей, продуктов и технологий в рамках этих отраслей, исходя из выделения групп проектов по критериям временной перспективы и возможностей ориентации на разные рынки (внутренний и внешний). В этой связи предложены и разные типы стратегий для потенциальных импортозамещающих проектов их разных отраслей.

Ключевые слова: импортозамещение, отраслевые проекты, стратегии развития проектов, показатели оценки потенциала отраслей.

В последние десятилетия в кругах ученых-экономистов часто звучали мысли о том, что все страны сейчас находятся на пороге новой промышленной революции, и постепенно ведущие экономики мира превращаются из производственных экономик в экономику услуг, но тем не менее, развитие производства остается важным направлением для обеспечения экономической и политической стабильности государства. Об этом свидетельствуют и происходящие в последние годы изменения в мировых экономических и политических отношениях, и пока продолжающаяся политика усиления санкций (в т.ч. ответных) различных государств по отношению друг к другу. Под санкции чаще всего попадают товары (продукция) и технологии, которые оказываются критически важными для конкретного государства, и по которым нет возможности очень оперативно и быстро начать производство адекватных по качеству и стоимости аналогов.

Поэтому сейчас Россия и некоторые другие государства, которые ранее придерживались концепции страновых конкурентных преимуществ (когда объективно признается, что производство какого-то продукта более целесообразно закупать из другой страны, нежели производить внутри в силу наличия объективных и труднодостижимых для своей экономики факторов конкурентоспособности), теперь снова вернулись к идее необходимости опираться на производственные возможности внутри страны. Однако, при всех преимуществах этого подхода, стоит учитывать ограниченность ресурсов как основную проблему, которая не позволяет государству развернуть разработку и производство импортозамещающих продуктов и технологий в относительно короткое время. При этом для распределения этих ограниченных ресурсов, необходимо учитывать еще и приоритетность развития этих отраслей. То есть, четко принимать, какие ресурсы и в каких отраслях использовать для развития импортозамещающих производств продуктов и технологий в первую очередь, а в какие - вкладываться только при наличии каких-то веских оснований.

Оценка потенциала отраслей промышленности в контексте импортозамещения изучалась в работах Федоськиной Л.А. [1], Фальцмана К.К. [2, 3], Смирнова В.В. [4], Крутовой М.А. [5] и ряда других исследователей.

При этом для оценки потенциала отраслей можно использовать группы из нескольких показателей, которые могут подбираться в зависимости от целей такой оценки. Например, это могут быть показатели:

- текущие и перспективные темпы развития отрасли (продукта, технологии);

- текущие и перспективные объемы потребления продукта/технологии;

- наличие/отсутствие в настоящий момент отечественных аналогов продуктов/технологий, их относительная конкурентоспособность в сравнении с лучшими образцами;

- издержки переключения на аналогичные

\footnotetext{
* Исследование выполнено при финансовой поддержке РФФИ, проект № 17-32-00037
} 
продукты/технологии из других стран;

- наличие нескольких альтернативных продуктов/технологий;

- количество отраслей, деятельность которых критично зависит от данных продуктов/ технологий;

- численность населения, которая пользуется данными продуктами и технологиями;

- время, необходимое для исследований, разработки и запуска отечественного продукта/ технологии-аналога;

- потенциал развития отдельных территорий государства при развитии производства продукта/технологии;

- наличие вторичных рынков для продукта/ технологии или их производных;

- возможность выхода с потенциальными отечественными разработками (продукты/технологии) на зарубежные рынки и пр.;

Если учитывать эти базовые параметры, все продукты/технологии, которые можно условно разделить на 3 группы (табл.).

Для оценки приоритетности и последующего принятия решения по каким-то конкретным проектам, будет важно как раз, смотреть в какую группу они предварительно попадают. При этом, следует понимать, что не все эти проекты будут инициироваться федеральными властями (т.е. относительно централизованно, часть из них вполне могут быть «инициативами снизу» и инициироваться региональными властями или даже отдельным компаниями-представителями бизнес. В этом случае такая система приоритезации проектов, если, к тому же она открытая, будет хорошим ориентиром для всех участников экономической и производственной деятельности, рассматривающих развитие своих предприятий, в том числе, через призму импортозамещения.
Другой момент, который необходимо учесть (уже на уровне государства) - это обязательное наличие в портфеле проектов по импортозамещению проектов из всех трех групп. Проекты первой группы позволят стартовать отраслям с низкими барьерами входа и относительно коротким производственным циклом (часть отраслей сельского хозяйства, переработки сельхозпродукции, или отрасли где отечественные разработки уже имеются и они могут на коротком отрезке времени стать конкурентоспособными с импортными). Вторая группа проектов может развернуть импортозамещение на чуть более отложенном отрезке времени, при этом используя относительные конкурентные преимущества территории (это могу быть почти все IT-проекты, переработка древесины, производство продуктов питания). И, наконец, третья группа проектов абсолютно необходима для обеспечения стратегической независимости РФ от импорта, и здесь, безусловно, должны инициироваться и поддерживаться проекты, связанные с достижением российской промышленности стратегических конкурентных преимуществ на мировых рынках (космическая промышленность, био- и медицинские технологии и др.).

Для каждой группы проектов будет требоваться совершенно разные подходы к их продвижению и управлению. Для этого можно опираться на уже существующие матрицы выбора стратегий, например, матрицу Ансоффа, или их модификации (рисунок).

Опираясь на такую классификацию проектов и базовые стратегии их развития, можно добиться значительно большей эффективности текущей программы по импортозамещению и обеспечению длительного стратегического эффекта на более длинном горизонте планирования.

Таблица. Описание характеристик групп потенциальных проектов по импортозамещению

\begin{tabular}{|c|c|c|}
\hline $\begin{array}{c}\text { Группа } 1 \text { - текущие } \\
\text { стратегические приоритеты }\end{array}$ & $\begin{array}{c}\text { Группа } 2 \text { - будущие } \\
\text { стратегические приоритеты }\end{array}$ & $\begin{array}{c}\text { Группа } 3 \text { - перспективные } \\
\text { проекты для отдельных отраслей }\end{array}$ \\
\hline $\begin{array}{l}\text { - значительное количество отрас- } \\
\text { лей, деятельность которых критич- } \\
\text { но зависит от данных продуктов/ } \\
\text { технологий, } \\
\text { - значительная доля населения, } \\
\text { которая пользуется данными про- } \\
\text { дуктами и технологиями, } \\
\text { - низкая конкурентоспособность } \\
\text { имеющихс отечественных разра- } \\
\text { боток (продуктов/ технологий) в } \\
\text { сравнении с лучшими образцами }\end{array}$ & $\begin{array}{l}\text { - высокие темпы развития отрас- } \\
\text { лей, где используются продукты/ } \\
\text { технологии на ближайшие 20-50 } \\
\text { лет, } \\
\text { - возможность выхода с потенци- } \\
\text { альными отечественными разра- } \\
\text { ботками (продукты/технологии) на } \\
\text { зарубежные рынки }\end{array}$ & $\begin{array}{l}\text { - высокие темпы продукты/ тех- } \\
\text { нологии на ближайшие } 20-50 \text { лет, } \\
\text { - наличие нескольких альтерна- } \\
\text { тивных продуктов/технологий, } \\
\text { - наличие вторичных рынков } \\
\text { для продукта/технологии или их } \\
\text { производных }\end{array}$ \\
\hline
\end{tabular}




\begin{tabular}{|c|c|c|c|}
\hline & & \multicolumn{2}{|c|}{ Товары, технологии } \\
\hline & & Старые & Новые \\
\hline \multirow{2}{*}{ 至 } & Старые & $\begin{array}{c}\text { Внедрение на рынок - быстрое разворачива- } \\
\text { ние производств внутри страны (приоритет } \\
\text { для группы 1) }\end{array}$ & $\begin{array}{c}\text { Развитие продукта/ технологии - доведение } \\
\text { до требований, близких или соответству- } \\
\text { ющих лучшим действующим образцам в } \\
\text { отрасли (приоритет для группы 2) }\end{array}$ \\
\hline & Новые & $\begin{array}{c}\text { Расширение рынка - использовать возмож- } \\
\text { ности выхода с имеющими (или минималь- } \\
\text { но модифицированными) продуктами и } \\
\text { технологиями на зарубежные рынки (прио- } \\
\text { ритет для группы 2) }\end{array}$ & $\begin{array}{c}\text { Диверсификация - развивать новые техноло- } \\
\text { гии, перспективные на горизонте 10-20 лет } \\
\text { (приоритет для группы 3) }\end{array}$ \\
\hline
\end{tabular}

Рис. Стратегии для импортозамещающих проектов (продуктов, технологий) по матрице Ансоффа

\section{Библиографический список}

1. Федоськина Л.А. Оценка потенциала импортозамещения региона: теория и практика на примере Республики Мордовия //Региональная экономика: теория и практика. № 3. 2016. С. 130-144.

2. Фальцман В.К. Импортозамещение в отраслях экономики России. Режим доступа: //https://ecfor.ru/wpcontent/uploads/2015/fp/5/05.pdf

3. Фальцман В.К. Форсирование импортозамещения в новой геополитической обстановке //Режим доступа: http://www.ecfor.ru/wp-content/uploads/2015/fp/1/03.pdf

4. Смирнов В.В. Повышение потенциала продовольственного импортозамещения регионов Российской Федерации //Аудит и финансовый анализ. № . 2015. С. 418-425.

5. Крутова М.А. Оценка потенциала импортозамещения в агропромышленном комплексе Российской Федерации //Современные научные исследования и разработки. № 3. 2016. С. 313-316. 